\title{
SIN SUELO NI LENGUA: EL PORTUÑOL COMO MEMORIA AFECTIVA. NOITE NU NORTE DE FABIÁN SEVERO
}

\author{
Without Land or Language: Portuñol as an Affective Memory. Noite un Norte \\ by Fabián Severo
}

\section{RESUMEN}

"Artigas tiene una lengua sin dueño", sentencia el poema "Nueve" de Noite nu Norte de Fabián Severo, libro de poesías escrito en portuñol, la lengua materna del autor. Es interesante notar que existen ya dos ediciones y que una y otra llevan subtítulos distintos: Poemas en Portuñol y Poesía de Frontera, de 2010 y 2011 respectivamente. Severo se define a sí mismo como una persona de la frontera, entre dos países, de acá y de allá, una mezcla que piensa y siente de una manera entreverada. La elección del portuñol respondería entonces a su propia identidad, a la manera en que él mismo se piensa. Pero además al sentimiento, es decir a la parte afectiva: pareciera ser que solo en portuñol Fabián Severo puede recuperar la voz de la infancia, esa voz de niño con la que recrea su propia infancia en el cruce con el Otro, en el espacio de la frontera.

\section{UNIVERSUM}

\section{MAYA GONZÁLEZ ROUX}

Instituto de Investigaciones en Humanidades y Ciencias Sociales, Universidad Nacional de La Plata. CONICET, Argentina.

Correo electrónico:

mayagonroux@yahoo.com.ar

ORCID: 0000-0002-8561-2799

ResearchGate:

Scholar.google:

Academia.edu:

Palabras claves: Severo - frontera - portuñol identidad - infancia 


\begin{abstract}
"Artigas has a language with no owner", says the poem "Nine" of Noite nu Norte by Fabián Severo, a book of poetry written in Portuguese, the author's mother tongue. It is interesting to note that there are already two editions and that both have different subtitles: Poems in Portuñol and Border Poetry, from 2010 and 2011 respectively. Severo defines himself as a border person, between two countries, from here and there, a mixture that thinks and feels in an intertwined way. The choice of Portuñol would then respond to his own identity, to the way he sees himself. But also to the feeling, that is to say to the affective part: it seems that only in Buenos Aires Fabián Severo can recover the voice of childhood, that voice of a child with which he recreates his own childhood at the intersection with the Other, in the space of the border.
\end{abstract}

Keywords: Severo - Border - Portuñol - Identity - Childhood

Escribir para no olvidar, dice una voz, la de Juan Nadie, en la primera poesía del libro Noite nu Norte (2010) de Fabián Severo. Esta voz, que en ese comienzo parece ligeramente discreta, algo áfona, irá adquiriendo poco a poco, a lo largo de todo el libro, un acento, o un tinte, que le atribuirá una identidad singular. Porque Juan es uno de los tantos Juan Nadie que vive en Artigas, lugar de frontera entre Uruguay y Brasil, y aquello que no quiere olvidar son los recuerdos de la infancia transcurrida en ese espacio intersticial. Escrito en portuñol, Noite nu Norte remarcaba desde el inicio su lengua de escritura con las palabras Poemas en Portuñol, un subtítulo que Severo decidió cambiar al año siguiente cuando tradujo el libro al español: Noche en el Norte. Poesía de Frontera, tal el título en su traducción al español, marcaba cierto anclaje territorial a pesar de conservar el título del original. ${ }^{1}$ Así, la tapa de la edición de 2011 colocó en espejo ambos títulos y lo que entonces se lee es Noite nu Norte. Noche en el Norte. Poesía de Frontera. Imposible pasar por alto la nocturnidad del Norte, así como el portuñol y la frontera. Lo dice la voz de Juan Nadie en aquella primera poesía: "Vo iscrevé las lembransa pra no isquesé" ["Voy a escribir los recuerdos para no olvidar"] ("Uno"). ${ }^{2}$

Noite nu Norte, con cincuenta y siete "micropoesías" (la versión en

1 Y, en su reciente traducción al inglés, Night in the North (Eulalia Books, 2020).

2 El portuñol del libro es una variedad del portugués uruguayo propia a Artigas, como 
español cuenta con una poesía más), deshilvana los recuerdos de la vida en Artigas, allí donde "viven los que tienen apeyido" (25), pero también la vida de "los Se ninguéim" (los "Juan Nadie" en la traducción al español) que se encuentran un poco alejados, en la frontera:

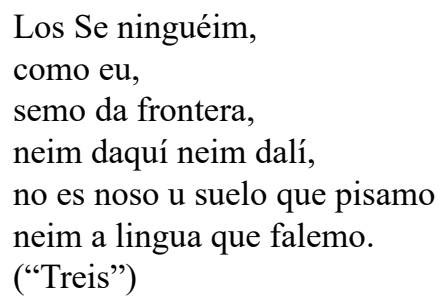

Las primeras poesías recuerdan la desposesión en la que se vivía, y la situación de despojo total. Se trata del vacío y de la soledad, de la tierra donde se habla una lengua huérfana como es el caso de Artigas. Por cierto, el despojo como única realidad en la que vivir, evidentemente impuesta, reaparece en su novela posterior, Viralata (2015), donde nuevamente se describe la vida de Artigas. ${ }^{3}$ Tal vez la sensibilidad que allí aparece sea una manera de entender el mundo que sin duda se anuda con el modo de percibir, y definir, su propia identidad. La palabra portuguesa "viralata" designa al ser que pertenece a dos géneros, específicamente a dos razas; resultado entonces del cruce de dos razas, los viralatas son los perros mestizos sin pedigrí. Viralata es la frontera,

veremos más adelante. A continuación se citará la primera versión de Noite nu Norte, en portuñol. Esta decisión obedece al deseo de escuchar la musicalidad del portuñol que se perdió en su traducción al español, según palabras del propio Severo. Pero indudablemente, en la elección del portuñol como lengua de escritura hay un proyecto estético y una determinación política que deseamos subrayar.

3 La ironía nuevamente asoma en Viralata en la escena de despojo que se produce ante la muerte de la madre y la posterior reunión de los parientes para repartir sus cosas. "Lo que quedaba de ella, se fue en los pie de una, en el bolso de otro, esparramándose en Artiga. [...]. Yo salí a caminar por el barrio. No quería ver aquella descascaración. No es que yo estuviera en contra o que mis pariente estivessem mal. En realidad, ellos me istaban ayudando aprender a vivir con el vacio. Todos pensaban que sería más fácil volver para casa y no encontrar la máquina de coser o las crema de ella en el baño". 
viralata es quien no tiene un origen. ${ }^{4}$

El vacío también concierne al tiempo porque en Artigas, el hijo que fue abandonado por la madre Montevideo, parece no haber futuro, y el tiempo solo puede medirse gracias a la sucesión de las estaciones. ${ }^{5}$ El sentimiento de orfandad al que se ven condenados sus habitantes expresa también la pobreza en la que viven: "Artigas ta feyado con candado". ("Sincu"), "Artigas e dumingo" ("Seis"), "Archigas no tiene presidente". ("Sete"), "Artigas teim uma lingua sin dueño" ("Nove"), "Nu verano / as tarde de Archigas soum das chicharra, / nu invierno, / de ninguém". ("Cuatru”), "Artigas e uma terra pirdida nu Norte / qui noum sai nus mapa". ("Onse"). Artigas también divide, marca diferencias porque "fala y baila com aqueles / mas trabaja y come con estos". ("Oito"). Sin embargo, hubo otro tiempo en el que Artigas era otro; cielo, río, campo y tierra estaban allí:

\footnotetext{
Artigas tevi um seu yeio distrela, um río yeio de peiye, um campo verde, asím de árbol, uma terra briliante de pedra, mas alguém levou tudo pra otru povo y nos fiquemo sein nada.

("Dose")
}

El tono inocente del yo que recuerda es la voz de un niño, como el personaje de Zezé en Mi planta de naranja lima de José Mauro de Vasconcelos. En el tono se mezcla la incomprensión propia de un niño con el deseo constante, pero también el orgullo y la ironía: "Antes / eu quiría ser uruguaio, / agora,

4 "La frontera es viralata. Tiene el pelo lacio de un país y la cara preta del otro. En los ladrido de la gente uno puede reconocer la raza porque todo se intrevera. ¿Qué tipo de árvore ía salir de acá si nosotro semo fío du vento? ¿Cómo nosotro no ía andar así, con un pie atrás y otro adelante, olfatiando antes de dar la mordida, si parece que nadies es el padre de nosotro? ¿Onde podemo preguntar si el color de nuestras oreja tiene algo que ver con el pasado de esta tierra?", Ibid.

5 Este "no tiempo" aparece nuevamente en Viralata, así, por ejemplo, asoma en la pasividad de los vecinos de Artigas a quienes les resulta inútil cortar el pasto, de hecho no lo hacen, ya que volverá a crecer. 
/ quiero ser daquí" ("Tresi”). Acá es Artigas, pero sobre todo la frontera de Artigas que se recuerda:

\author{
Veyo que todos se van. \\ Vaum variá pelu mundo. \\ Disapareseim. \\ Dis que hai vida la fuera, \\ eu noum sei, \\ so cuñeso esta sidade. \\ ("Quinse").
}

Hay un efecto "tragicómico" que logra la inocencia del tono en el recuerdo de la gran ciudad, Montevideo. Así, por ejemplo, el poema "Deseséis": "Uma ves fui pra Montevideu / y casi inloqueso. / Yo perguntava / meu Deus, pra que tanta yente". Pero, sobre todo, la búsqueda de ese tono responde al deseo de Severo por escribir una poesía que aborde temas sociales, esto es la pobreza, la miseria cotidiana de la vida de pueblo que se vive en un barrio de la frontera, sin que la escritura se convierta en un panfleto: el tono tragicómico de quien recuerda como un niño permite desdramatizar la miseria de la pobreza. El intento de crear ese tono, explicó el autor en una entrevista, "se liga a otra dimensión: la de lo 'tragicómico' que es un tono característico de la frontera, el hecho de decir las cosas más dramáticas con una dosis de humor. La frontera dicha por un niño no es tan trágica como podría ser la mirada de un adulto frente a la miseria, el hambre". ${ }^{6}$ Por eso los cumpleaños que tanto le gustaban al niño, pero a los que casi nunca podía ir por falta de ropa o de regalo, se recuerdan siempre como una fiesta ("Trintiuno"). $\mathrm{O}$ el dicho "quien madruga dios lo ayuda" que le repetía el vecino Fito, trae consigo el recuerdo de la obtención de comida: en la casa, a quien madrugaba Dios lo ayudaba porque podía comer el pan del día anterior, y quien no, debía esperar hasta el mediodía para comer.

A Cuaraí, una pequeña localidad del otro lado de la frontera, se va a

6 Enrique Foffani, "Entrevista con Fabián Severo: en Montevideo, lejos de la frontera", Katatay, septiembre 2012: 50. 
comprar alimentos, ese "surtido" que en varias ocasiones le roban al cruzar la frontera, obligándolo nuevamente a pedir fiado en el almacén ("Vinte"). La frontera también es el río Cuareim, límite con Brasil, un río que "asvés canta, asvés dorme. / Vai pra abajo, y se vai, se vai asta noum sei onde". ("Disenove"). En la imaginación del niño, los peces del Cuareim son libres, y "se van con el río, / se van para onde ele termiña, / disque es nu mar, / um lugar aonde la agua noum toca la tierra". ("Disenove", subrayado mío). En el cruce de la frontera se produce el intercambio de mercancías, y también con frecuencia el despojo. La poesía "Vintiún" enlaza esta frontera geográfica, con aquella otra, tal vez más dolorosa en la voz de quien recuerda:

\author{
Serto día que yo istava triste \\ purque me tiñan quitado tudo \\ lo que trasía de Brasil, \\ mi tío, ques soldado y viayó por todo u mundo, \\ me dice: \\ noum te queya, \\ porque tein lugar aonde ni te deiyan entrá. \\ Yo ayo que ele dise iso porque yo soy burro \\ y no terminé la escuela. \\ Purque si Deus isiste y semo todos hijo del, \\ como vai avé lugar aonde no te deiyen entrá.
}

\title{
EL PORTUÑOL, LENGUA AFECTIVA
}

En la localidad de Artigas, aquella que recrea Noite nu Norte, esa otra frontera es también la de la lengua. La frontera ya no es solo geográfica, o el otro lado donde se produce la compra de mercancías, sino que en esta otra frontera tiene lugar otro tipo de intercambio, esta vez entre lenguas, entre el portugués y el español. Sin duda, en este sentido, la escuela prefigura otra frontera, la del acceso al español como norma y lengua de enseñanza: 
Yo no quiría ir mas en la escuela

purque la maestra Rita, de primer año

cada ves que yo ablava

pidía para que yo repitiera y disía,

vieron el cantito na vos del, asín no se debe hablar

y todos se rían de mim,

como eya pidía que yo repitiera

yo repitía y eyos volvían se ri.

("Treinta y dos").

El "portuñol se fala", como dice Severo, y la distinción entre "falar" y "hablar" es la escuela la que la normaliza:

Mi madre falava mui bien, yo intendía.

Fabi andá faser los deber, yo fasía.

Fabi traseme meio litro de leite, yo trasía.

Desí pra doña Cora que amañá le pago, yo disía.

Deya iso gurí y yo deiyava.

Mas mi maestra no intendía.

Mandava cartas en mi caderno,

todo con rojo (igualsito su cara) y asinava imbaiyo.

Mas mi madre no intendía.

Le iso pra mim hijo y yo leía.

Mas mi madre no intendía.

Qué fiseste meu fio, te dise que te portaras bien

y yo me portava.

("Trinticuatro")

Y así durante muchos meses, la maestra escribía en el cuaderno que él luego le leía a su madre, pero que ella seguía sin poder entender. Hasta que un día entendió y dijo: "Intonses serto día mi madre intendió y dise: / Meu fio, tu terás que deiyá la iscuela / y yo deiyé". ("Trinticuatro"). La escuela dictamina - lo que se entiende y lo que no-, y discrimina. Así, cuando un día en la feria junto a su madre un hombre la saluda con el nombre de "Puchero", ella le cuenta al niño que cuando iba a la escuela siempre estaba sucia y mal vestida, y que los útiles los llevaba en una bolsa de azúcar. Un día, la maestra 
se acercó y le dijo: "La verdá que este cuaderno tiene de todo, / solo le falta grasa pra ser un puchero". ("Trintiséis"). El recuerdo de ese nombre le trae mucha tristeza; mejor es olvidar.

Además de dictaminar y discriminar, la educación sistematiza a través de la enseñanza en español, pero cuando el niño abandona la escuela permite que su propia lengua se imponga porque si el portuñol "se fala", como señalaba Severo, también "le saca la lengua al disionario, / baila um pagode ensima dus mapa / y fas com a túnica y a moña uma cometa / pra voar, livre y solta pelu seu". ("Des"). La túnica, símbolo de la escuela en Uruguay, convertida en una cometa, deja entrar al "español de frontera" para que más tarde se convierta en escritura del recuerdo. Esto es, para que el niño haga historia, como un día su padrino se lo sugirió, el español debe permanecer retirado, volverse lengua afásica y así dejar "falar al portuñol":

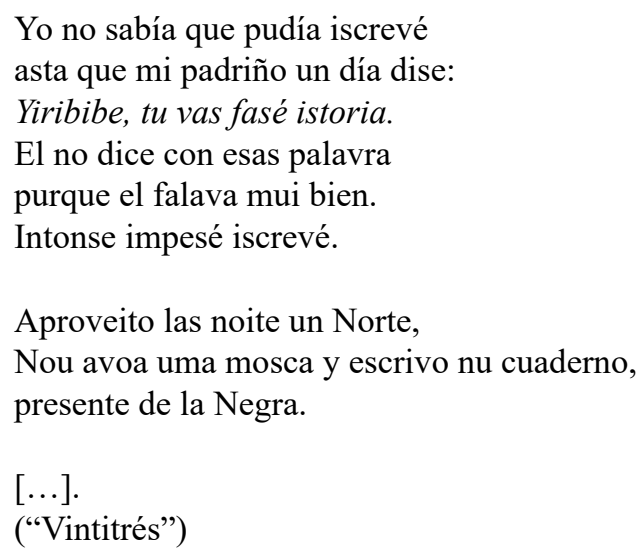

Los otros, "aqueles nou presta pra nada, so pra fofoca", es decir aquellos que solo sirven para el chusmerío, son los que no pueden escribir, que no podrán dejar asentada su propia historia para mostrársela a sus hijos cuando pregunten, porque "los gurí de agora son una lus, / quereim sabé tudo y noum se calam nunca". ("Vintitrés").

Es conocida la presencia del portuñol en Artigas, no solo "se fala" sino que también puede verse en los carteles de los comercios del barrio o en los 
bordes de los billetes, en los márgenes. Es diverso porque cambia de acuerdo al barrio y las generaciones. Lo cierto es que el portuñol del poeta no tiene gramática ni norma, es una "variedad ágrafa del portugués con mayor o meno[r] influencia del español, que las personas de Artigas utilizan cotidianamente", reflexiona en el prólogo a la primera edición del libro Luis Behares, al remarcar, además, que Severo escribe desde una situación de exilio lingüístico porque lo hace desde Montevideo donde enseña en español. ${ }^{7}$ ¿Por qué la elección de Severo de escribir en su lengua materna, en su portuñol? Lengua apátrida para algunos, para otros "devastación del español y del portugués, [...] lengua fea, de gentes feas y de escaso interés intelectual y cultural”, el portuñol de Severo, una lengua que se ve obligada a "innovar e improvisar" a falta de gramática, se convierte en un "acto de amor a su lengua materna", una "manifestación fuerte de deseo de entidad, de permanencia y de integridad". ${ }^{8}$ Pero, por sobre todo, se trata de un gesto político de creación de identidad, cuyo rasgo principal es la riqueza que le ofrece la frontera. Y esto es así porque, si bien es verdad que en la elección de "su portuñol" hay una carga afectiva muy importante, al punto que Severo aseguró en la entrevista anteriormente citada que algunas cosas él solo podía expresarlas en su lengua materna artiguense y que por ello mismo había lamentado, en cierto sentido, la traducción de Noite nu Norte al español, no lo es menos el hecho de que esa elección de la lengua de escritura reviste un carácter social y, con él, político. ${ }^{9}$ La poesía "Nove" es contundente al respecto: "Artigas teim uma lingua sin dueño". A ese sentimiento de orfandad

7 Luis Behares, “Transliteraciones fronterizas”, Noite nu Norte, op. cit., 10.

8 Ibid., 11 y 15.

9 Sin duda, el carácter político del gesto permite comprender el portuñol del autor como un fenómeno vinculado con el campo de la glotopolítica, concepto que, al englobar y neutralizar la oposición entre lengua y habla, como asentaron Guespin y Marcellesi, permite designar las distintas perspectivas - acciones que revisten una forma política - que una sociedad ejerce sobre el lenguaje: ya sea la lengua (por ejemplo, al establecer ciertas reglas gramaticales que, en el caso preciso del portuñol, es interesante de señalar porque justamente no existe ninguna gramática), el habla (cuando reprime determinado uso), o el discurso (cuando la escuela promueve la evaluación de un tipo de texto). $C f$. Louis Guespin y Jean-Baptiste Marcellesi, "Pour la glottopolitique", Langages, n. ${ }^{\circ} 83,1986: 5-34$ (5). Véase también Elvira Arnoux, "La Glotopolítica: transformaciones de un campo disciplinario", Lenguajes, teorías y prácticas, 2000: $1-18$. 
se agrega el deseo de encontrar una voz artiguense y de definir una "identidad fronteriza" en la que el portuñol, tal como lo explica Fabián Severo, sin duda es sumamente significativo para todo artiguense al momento de construirse como sujetos sociales a partir de la lengua. ${ }^{10}$ Todo sujeto se piensa al interior de una lengua y, en el caso de Severo, él imagina, recuerda, se define en portuñol. Y tal vez también, sueñe en esa lengua.

Así como la frontera en Severo determina menos un límite que, por el contrario, un constante paso, una errancia de un lado hacia el otro, la ausencia de gramática del portuñol promueve también otra errancia. Errar, entonces, en las dos acepciones del término. Esto último es lo que defendió Perlongher al resaltar el valor del portuñol como lengua poética en la que percibía una gran riqueza en el constante errar entre el portugués y el español: los deslizamientos de una lengua a otra, propios al portuñol — "travesura del idioma frente a la careticie [de careta] de las lenguas oficiales", se reía Perlongher- hacen que el lugar desde el que el poeta habla sea movedizo e inestable, imprevisible y precario. ${ }^{11}$ Ante este panorama, el poeta no puede más que improvisar y es lo que precisamente hace Fabián Severo con su portuñol. Improvisa en y desde la lengua, pero también "trafica", roba, o mejor aún, contrabandea. En este sentido, es posible evocar una primera imagen del bagayero para pensar la figura del poeta. El bagayero es aquel que a través de la frontera practica el contrabando entre el portugués y el español, dibujando sonidos y expresiones, combinando palabras, inventando verbos o conjugaciones. ${ }^{12}$ La lengua materna se convierte en un lugar de contrabando en el que prima la indistinción entre lo propio y lo ajeno; ya lo anunciaba la poesía "Vintidóis", al afirmar que "Si eyos se levam lo que fasemo / purqué nou podemo trasé lo que eyos fasen".

Dicho esto, el exilio que se mencionó antes comenzaría no en el momento en que el poeta deja la ciudad de Artigas, sino cuando la lengua, el portuñol que habla su familia y sus ancestros, es olvidado, relegado, murmurado. Qué

10 Enrique Foffani, "Entrevista con Fabián Severo...”, op. cit.,53.

11 Néstor Perlongher, "El portuñol en la poesía”, Tsé Tsé, 2000: 254.

12 En una entrevista televisiva, Severo se refirió a su trabajo creativo en términos de "bagayeo", de traficar y pasar al portuñol muchos fragmentos de otros libros. 
es el exilio, se preguntaba Jacques Hassoun, sino la puesta en funcionamiento de una artimaña inconsciente que intenta olvidar la multiplicidad de lenguas inmersas de la infancia. Justamente, la lengua en que se enuncian esas evocaciones de un pasado ya desaparecido y de una tierra lejana, y por qué no algo oculta, es lo que Hassoun llamó la "lengua de contrabando". Toda literatura, por lo tanto, tanto en sus páginas más sublimes como banales, va a contener paisajes y perfumes, barbarismos y hechos olvidados que dan cuenta de que en lo más profundo de nuestra subjetividad siempre palpita esa cosa viva, la lengua de contrabando. ${ }^{13}$ Suerte de tesoro lingüístico, como una propiedad de quien cree ser el depositario, la lengua de contrabando es inaudible para los otros y remitiría para el exiliado a una fuente de imágenes borrosas o incluso reducidas al estado de huella. Puede suceder también, continúa Hassoun, que esta lengua aparezca como en filigrana en la otra lengua, por caso en el francés de Albert Cohen o en el alemán de Elias Canetti: es lo que constituye el estilo propio de cada autor, esa huella en filigrana comparable a un perfume único. ${ }^{14}$ El portuñol es justamente fuente de imágenes para Severo quien, a través de la figura del bagayero a la que se aludió más arriba, intenta escapar a la lógica de la frontera como división e instalar, en consecuencia, su casa no de un lado o del otro de la frontera, sino en ambos lados, es decir, en el universo del afecto. Repleta de sonidos, ritmos, ecos y acentos - lejos entonces del despojo y del vacío-, su morada representa esa musicalidad del portuñol natal.

La musicalidad de su lengua, en la voz del niño, permite alcanzar una forma simple y perfecta que es a la que aspira Severo: la sencillez perfecta consiste en decir las cosas más importantes en una forma simple, tan simple que roce la perfección. ${ }^{15}$ En las últimas poesías, si bien los versos se condensan

13 Jacques Hassoun, L'exil de la langue, París: Point Hors Ligne, 1993: 66.

14 Jacques Hassoun, "Langue maternelle... Terre ultime?", Horizons maghrebins - Le droit à la mémoire, $\mathrm{n}^{\mathrm{o}} 16,1991:$ 40-48 (43-44).

15 "Lo que busco es, en definitiva, una economía que haga que la historia sea contundente", entrevista a Fabián Severo, 52-53. Una economía que sin duda se refuerza en la voz del niño asombrado por el exceso. Así, después de mucho imaginar cómo sería la mansión del doctor Cardoso, una vez allí "no intendía pra que tiña tantas piesa. / Havía mucho cuarto, muinto baño, mucho tudo". ("Trintinove"). Sin duda, en la voz de un niño logra esa sencillez perfecta, 
en la misma sencillez perfecta de estilo, el tono es otro. Los recuerdos de la infancia se disipan, entre ellos la vida de barrio y la relación con los vecinos, así como la evocación de su casa a la que llama "caja de fósforos", los juegos compartidos, la falta cotidiana de comida en contraposición con el lujo que el niño observa, por ejemplo, en la casa del médico cuando va a una consulta, o la escuela como lugar de segregación. El tono jocoso se retrae y asoma un tono más reflexivo y asertivo: "A vida e asím, / cuanto menos um tein / mas luta pra sobreviver". ("Sincuenticuatru"); "Cuando uno es pobre / y eu so pobre, / no puede isquesé de aonde viene". ("Sincuentisincu").

Un poco más adelante, la poesía "Sincuentiséis" se lee como una sentencia: "Eu noum sei / si algún día voy incontrá la felisidade. / La noite nu Norte es muy difísil". Sin embargo, a pesar de ese "eu noum sei", la noche orientada hacia el Norte es una certeza porque, como se sabe, "perder el Norte" es la expresión de la desorientación. La noche en el Norte indica un comienzo, un nacimiento como interpreta Foffani, ya que "tener un norte es estar orientado, tener un rumbo, la (co)rrecta dirección hacia el futuro, allí donde sentido es también, anagramáticamente, un destino". ${ }^{16}$ El sentido está en el Norte que quien recuerda, quien escribe para no olvidar, no pierde. Y ese Norte es el de la frontera que, una vez más, Fabián Severo pondrá en primer plano en su novela Viralata: en la frontera todos son vira-lata, se tienen orejas de una raza y patas de otra. Es también la figura del árbol que aparece con más insistencia en este último libro, el árbol como lugar de encuentro y de cobijo. Pero es un árbol que no tiene raíces, hueco por dentro y con genealogías "entreveradas" que recuerdan a la gente de la frontera, tal como la definió Severo, una mezcla que piensa y siente de un modo entremezclado. Es esa mezcla que la poesía de Noite nu Norte intenta captar y que para Severo compone la voz artiguense. Resulta difícil, sin embargo, definir sus componentes e incluso tal vez sea una tarea vana, como si al distinguir finalmente se estuviese disecando esa voz que

ya que "creser es deiyá de jugar" ("Trinta”).

16 Enrique Foffani, "La frontera Uruguay-Brasil: Fabián Severo, el poeta sin gramática", Katatay, 2012: 48. 
encuentra su esencia en la mezcla.

La poesía recrea por lo tanto aquello que existe en el plano de la experiencia, la pluralidad de la identidad cultural de esa frontera cuyos rasgos recuerdan otro espacio, también fronterizo, pero de otra geografía: la triestina, de Claudio Magris. Al reflexionar sobre la identidad de su ciudad natal Trieste, en el libro Trieste, Un'identità di frontera, Magris reconoce la dificultad que existe al querer identificar sus tres componentes, eslavo, alemán e italiano. Así se definía el escritor Scipio Slataper en una carta a su mujer y que Magris cita al explicar que esa autodefinición solo existe en el plano de lo vivido y de la poesía que la recrea pero que escapa a toda connotación individual precisa. Slataper, a pesar de su origen eslavo, se alejó de ese mundo, explica Magris; por otro lado, en ciertos aspectos era alemán por su formación, pero se sentía diferente a los alemanes $\mathrm{y}$, finalmente, italiano en otros aspectos, pero no era un italiano como los otros. Su identidad, y esto resulta fundamental para comprender el valor existencial que le otorga a la literatura y que sin duda es un gesto fundacional que también se lee en Noite nu Norte, solo puede encontrarla en la expresión que le otorgó a su imaginario: Trieste es literatura, su literatura, y Svevo, Saba - los otros dos escritores que cita Magris como ejemplos - y Slataper son menos escritores que nacieron allí que, a la inversa, escritores que la engendraron, que la crearon y le dieron un rostro. ${ }^{17}$ En esta línea habría que pensar los vínculos de Severo con el espacio de la frontera: sin caer en esencialismos o abstracciones de rasgos típicos, logra otorgarle un rostro a Artigas, un rostro entreverado justamente, cuyas líneas son los rasgos que va dibujando el portuñol, siempre errante, como la gente de Artigas:

17 Claudio Magris, Trieste. Une identité de frontière, 23. 
Todos nos semo da frontera,

como eses pásaro avuando de la pra qui

cantando um idioma que todos intende.

Viemos da frontera, vamo pra frontera, como us avó y nosos filio, cumendo el pan que u diabo amasó, sofrendo neste fin de mundo.

Nos semo da frontera, mas que cualqué río, mas que cualqué puente. ("Sincuentisete").

Venimos de la frontera y hacia ella vamos, como nuestros abuelos y nuestros hijos. En estos últimos versos persiste el deseo de transmitir un pasado - "voy a escribir los recuerdos para no olvidar", decisivo comienzo de la poesía "Uno"-, una transmisión que forzosamente debe ser entreverada como su lengua. Alejarse de todo esencialismo identitario, dejar que en la lengua se infiltre lo que a cada uno le es propio y preciado, y que la norma tiende a anular — volvamos al primer verso de la poesía "Des", "Miña lingua le saca la lengua al disionario"-, es lo que Jacques Hassoun denominó ser contrabandistas: solo así se logra transmitir, aceptando que el purismo de la lengua, su inmovilidad o estabilidad son una trampa. No temamos ser contrabandistas, continúa Hassoun, todos somos exiliados, como trashumantes que han quemado sus naves. ${ }^{18}$ Sin embargo, lo que no han perdido los exiliados es su acento: el acento revela, denuncia y traiciona, según Alain Fleischer, "a un pasajero clandestino, a una lengua fantasma, al fantasma de una lengua escondidos en la lengua que el locutor actualiza, [es] a la vez una forma de memoria y la marca de una diferencia, la incapacidad a la semejanza absoluta". ${ }^{19}$ De este modo, es posible imaginar con más nitidez a Severo a

18 Jacques Hassoun, L'exil de la langue, op. cit., 66-67. [Traducción nuestra].

19 Alain Fleischer, L'Accent, une langue fantôme, París, Éditions du Seuil, 2005: 78. [Traducción nuestra]. 
través de la figura de bagayero que contrabandea entre lenguas, el español y el portugués, cruzando la frontera constantemente, traficando de un lado y del otro. Pero no está solo, no está totalmente despojado, sino que lleva consigo su acento que nunca pierde y que siempre persiste.

\section{REFERENCIAS}

Arnoux, Elvira. "La Glotopolítica: transformaciones de un campo disciplinario", Alfredo Rubione (ed.), Lenguajes, teorías y prácticas. Primer Simposio de la Maestría en Ciencias del Lenguaje-1999, Gobierno de la Ciudad de Buenos Aires, I. S. P. Joaquín V. González, 2000: 95-109.

Behares, Luis. "Transliteraciones fronterizas", Noite nu Norte. Poemas en Portuñol. Montevideo: Ediciones del Rincón, 2010: 9-16.

Fleischer, Alain. L'Accent, une langue fantôme. París: Éditions du Seuil, 2005. Foffani, Enrique. "Entrevista con Fabián Severo: en Montevideo, lejos de la frontera", Katatay, 10, La Plata, (2012): 50-55.

"La frontera Uruguay-Brasil: Fabián Severo, el poeta sin gramática", Katatay, 10, La Plata, (2012): 43-49.

Guespin, Louis y Marcellesi Jean-Baptiste, "Pour la glottopolitique", Langages, 83, 1986: 5-34.

Hassoun, Jacques. L'Exil de la langue. París: Point Hors Ligne, 1993.

"Langue maternelle... Terre ultime?", Horizons maghrebins - Le droit à la mémoire, 16, (1991): 40-48.

Magris, Claudio. Trieste. Une identité de frontière. París: Éditions du Seuil, 1991.

Perlongher, Néstor. "El portuñol en la poesía": Tsé Tsé, 7/8, Buenos Aires, (2000): 254-259.

Severo, Fabián. Noite nu Norte. Poemas en Portuñol. Montevideo: Ediciones del Rincón, 2010. 
Viralata. Montevideo: Rumbo Editorial, 2015.

Entrevista televisiva: https://www.youtube.com/ watch? $\mathrm{v}=$ MnDFGUE2H_s (consultada el 25/10/19) 